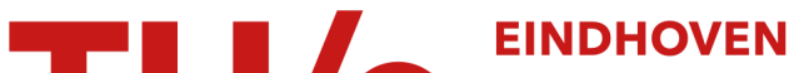 \\ UNIVERSITY OF \\ TECHNOLOGY
}

\section{On the modeling of continuous mixers. Part II: The cokneader}

Citation for published version (APA):

Elemans, P. H. M., \& Meijer, H. E. H. (1990). On the modeling of continuous mixers. Part II: The cokneader. Polymer Engineering and Science, 30(15), 893-904. https://doi.org/10.1002/pen.760301504

DOI:

10.1002/pen.760301504

Document status and date:

Published: 01/01/1990

\section{Document Version:}

Publisher's PDF, also known as Version of Record (includes final page, issue and volume numbers)

\section{Please check the document version of this publication:}

- A submitted manuscript is the version of the article upon submission and before peer-review. There can be important differences between the submitted version and the official published version of record. People interested in the research are advised to contact the author for the final version of the publication, or visit the $\mathrm{DOI}$ to the publisher's website.

- The final author version and the galley proof are versions of the publication after peer review.

- The final published version features the final layout of the paper including the volume, issue and page numbers.

Link to publication

\section{General rights}

Copyright and moral rights for the publications made accessible in the public portal are retained by the authors and/or other copyright owners and it is a condition of accessing publications that users recognise and abide by the legal requirements associated with these rights.

- Users may download and print one copy of any publication from the public portal for the purpose of private study or research.

- You may not further distribute the material or use it for any profit-making activity or commercial gain

- You may freely distribute the URL identifying the publication in the public portal.

If the publication is distributed under the terms of Article $25 \mathrm{fa}$ of the Dutch Copyright Act, indicated by the "Taverne" license above, please follow below link for the End User Agreement:

www.tue.nl/taverne

Take down policy

If you believe that this document breaches copyright please contact us at:

openaccess@tue.nl

providing details and we will investigate your claim. 


\title{
On the Modeling of Continuous Mixers. Part II: The Cokneader
}

\author{
P. H. M. ELEMANS* and H. E. H. MEIJER \\ Department of Mechanical Engineering \\ Eindhoven University of Technology \\ 5600 MB Eindhoven, The Netherlands
}

\begin{abstract}
The Buss cokneader is a single-screw extruder with interrupted flights. Pins from the barrel are inserted into the screw channel. The screw is both rotating and oscillating. Due to this action, screw flights are continuously wiped by the pins. During one passage of the pin, the material is not only subjected to high shear stress, but it is reoriented as well, thus promoting the distributive mixing process by the local weaving action of the pins and screw flights. Attempts to model the cokneader tend to focus on a single pin passing through the hole in a screw flight $(1,2)$. However, a more comprehensive model can start with the same equations that apply to the corotating twin-screw extruder (3). Because the effect of leakage flows on the local pressure gradient has to be considered along with the effect of the local dragging action of the pins (neglecting the oscillatory action), experiments with model liquids have been performed to evaluate the comprehensive model. Additional experiments with a Plexiglas-walled cokneader support the calculations concerning filled lengths in various screw geometries. These results, and those of model calculations, which are extended to the nonisothermal, nonNewtonian situation, are presented.
\end{abstract}

\section{INTRODUCTION}

$\mathrm{T}$ he Buss cokneader is a continuous mixer that is widely used in many operations in the processing of polymers and foodstock. It offers possibilities for homogenization, coloring, reinforcing, and especially filling of critical and difficult-to-handle compounds of thermoplastics, rubbers, or thermosets (4-7). Provided the metering of the individual components is correct, torque and temperature rise can be kept well under control, even for thermally unstable materials and/or critical additives, partly because both screw and barrel are oil thermostated.

Since its 1945 invention (8), practical application of the cokneader has been far ahead of theoretical understanding. According to the design specifications, the cokneader is said to operate fully adiabatically, and scaleup should be no problem since "every next size in the series has tenfold the throughput of the previous size (PR46, PR100, PR200)." Although the more modern machines have not been altered in the main working principle, their length has been increased from 7D to 11D (for special purposes even $15 \mathrm{D}$ can be chosen) and screw and barrel designs are flexible now. This flexibility requires the development of models that can give predictive answers with regard to energy, specific energy, temperature rise,

- Present address: DSM Research BV. P.O. Box 18, 6160 MD Geleen, The Netherlands. and residence time, dependent on metered throughput, screw design, and operating conditions.

Recently, one of the first more serious studies concerning the modeling of flow in pin-barrel (rubber) extruders appeared (9). Like Ref. 1 , it is confined to calculations of one type of screw element of invariable geometry (no sequence of different screw elements as used in the cokneader). The flow is said to be Newtonian and isothermal. However, it can be expected that processing of highly viscous model fluids will give rise to a considerable increase in melt temperature. Moreover, the mixing of pin screw extruders used in rubber processing is much less effective than that of the weaving action of the pins and remaining screw flights in the cokneader because of its rotating and oscillating movements (see Fig. 3). Besides, apart from improved mixing performance (see Ref. 10), one of the most important effects of the pins in rubber extruders could be the improvement of the transport characteristics by breaking through slip layers in the beginning of the process where an extremely high viscous, plastic material is present. Kneading is normally promoted in these types of extruders by the choice of the screw: multichannel, multicompression, and decompression with many local barrier flights.

It would be interesting to compare the results of Ref. 9 with experiments in those sections of rubber extruders where only melt is present and the models 
apply. Here, we tried to model the Buss cokneader in a way analogous to that of the corotating twin-screw extruder (3). First we will only deal with the simplest case of a Newtonian liquid under isothermal conditions. This analysis can be extended, as in Ref. 3, to the non-Newtonian, nonisothermal situation of a melt-fed cokneader.

\section{SCREW GEOMETRY AND WORKING PRINCIPLE}

The screw of a cokneader consists of interchangeable elements. Figure 1 shows three common screw elements: conveying elements (single flighted), having two rows of two pins per lead inserted in the barrel; closed channel kneading elements, double flighted, with three rows of one pin per lead; and kneading elements, also double flighted and having three rows of two pins per lead.

In contrast to the corotating twin-screw extruder, no real negative transporting elements exist, except for the element shown in Fig. $6 e$, which has a locally negative pitch angle. Staggering elements, however, are used. The most common ones are buffle rings, used preceding degassing sections in the barrel, and the die that connects the kneader to the discharge extruder if present (see Figs. $2 a$ and $2 b$ ).

An alternative setup, which replaces the discharge extruder to assure regular material outflow as proposed in Ref. 11, is discussed in the section Experimental.

Figure 3 illustrates the combined (self-wiping) action of the interrupted flights of a kneading element with the corresponding kneading bolt in the barrel wall (the kneading bolts are usually diamond-shaped, except in the PR46, which has cylindrical bolts). It is due to this weaving pattern that the cokneader pos-

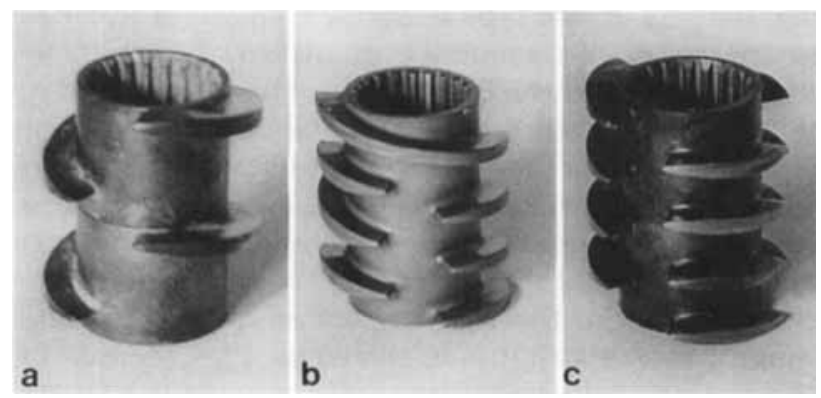

Fig. 1. Common screw elements: (a) conveying (2 rows of 2 pins); (b) closed channel kneading (3 rows of 1 pin); (c) kneading ( 3 rows of 2 pins).
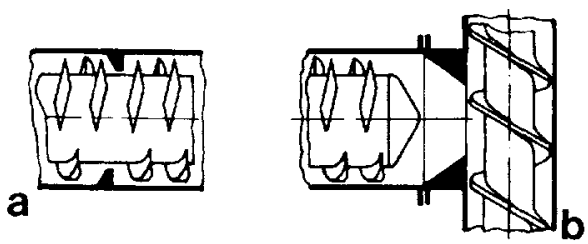

Fig. 2. Staggering elements (schematically, after Ref. 3): (a) buffle ring: (b) die connecting kneader and discharge extruder. sesses an excellent distributive mixing quality. The unrolled "standard screw" geometry (Fig. 4) clearly shows the variety in mixing intensity along the screw.

\section{SUMMARY OF THE NEWTONIAN, ISOTHERMAL ANALYSIS}

As in the case of a corotating twin-screw extruder, the analysis of the cokneader will depart from the combination of a screw element (conveying or kneading) with a staggering element. The screw elements of the cokneader all have interrupted flights, leaving room for the pins to pass during each revolution. Thus, two main influences on the usual drag-andpressure flow can be distinguished: (i) the extra conveying action due to the pins, and (ii) the leakage flow through the flights' holes, back into the previous channel. The remaining screw flight is a factor, $r$, of the total length of the screw flight $\left(L_{f}=r \cdot \pi D / \cos \varphi\right)$. The sum of the holes' length equals the factor (1 $r$ ). The pins are thought to cause a plug flow right in front of them:

$$
Q_{p i n}=n V H d_{p i n} .
$$

However, because this plug flow will merely promote leakage through the flights, an efficiency parameter for the flow due to the pins in down-channel direction is added:

$$
Q=\varepsilon \cdot Q_{p i n}
$$

The value of $\varepsilon$ will be close to zero and can be evaluated from a local three-dimensional analysis, but will
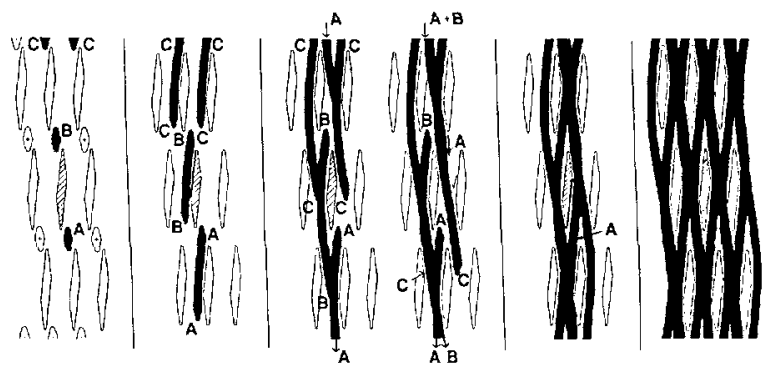

Fig. 3. Trajectories of (stationary) pins relative to the shaded flight (Figs. 3a-3d). Fig. 3e shows the weaving pattern as a result of the motion of the pins.

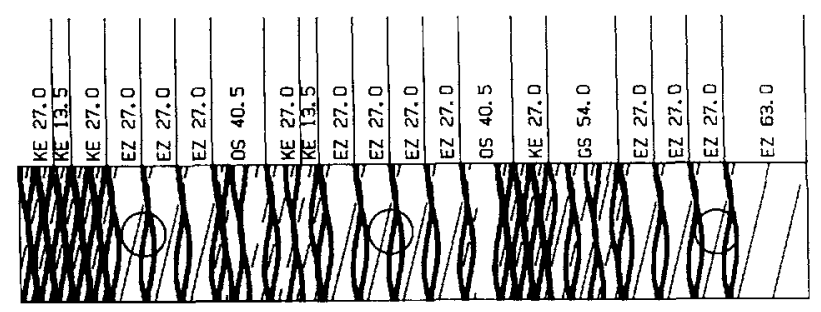

Fig. 4. Unrolled "standard screw" geometry $(D=46 \mathrm{~mm}$. $L / D=11)$ showing the sinusoidal trajectories of the pins relative to the screw. The circles indicate the feed ports. Explanation of screw element abbreviations: EZ, conveying: KE, kneading; GS, closed channel kneading; OS, buffle ring. 
be determined experimentally in this investigation. Where pins are present, no drag flow will exist. This is expressed by the dimensionless geometrical factor $\alpha$, the aspect ratio of the pins' surface over the channel surface:

$$
\alpha=\left(d_{p i n}\right)^{2} /(L \cdot W / n) .
$$

The drag flow is diminished with increasing values of $\alpha$ :

$$
Q_{d_{\text {iutth ptns }}}=(1-\alpha) \cdot Q_{d_{\text {iwithout pinst }}}
$$

Inspection of Table 2 reveals that the practical values of $\alpha$ are, however, quite small. The two influences (pins and leakage flow) are investigated separately in order to understand the transport characteristics of the kneader.

Although the kneader is rotating as well as oscillating in the axial direction, we will neglect the influence of the latter in the analysis of the transport characteristics. The equations for Newtonian, isothermal pressure and drag flow in an unrolled screw channel will be applied, with the usual assumptions, including the neglect of pressure flow over the flight clearance (3). It must be noticed here that Ref. 3 contains an omission with regard to the pressure flow in axial direction, which is only of relevance in nonneutral kneading elements. The adaptations necessary in Table 4 of Ref. 3 are summarized in the Appendix. Table 1 gives the resulting equations that apply to the cokneader. Because of the large number of relatively big holes in the interrupted screw flights of the cokneader, the flow rates due to local pressure gradients are important not only in the down-chan- nel direction, but also in the axial direction. In Fig. 5 , the pressure gradients in the surroundings of a hole are visualized in the unrolled screw. The pressure difference $\Delta P$ between the two points $A$ and $B$ in the screw channel can be expressed by two different routes, either by a distance $z$ in positive $z$-direction: $\Delta P=(d p / d z) \cdot z$, or by a distance $x$ in negative $x$ direction: $\Delta P=(d p / d(-x)) \cdot x$. The pressure flow equals the pressure gradient times a geometrical resistance factor $k$ for that particular direction; see $E q$ 5 of Table 1. The coordinates $x$ and $z$ are related to the axial coordinate, $\ell$ :

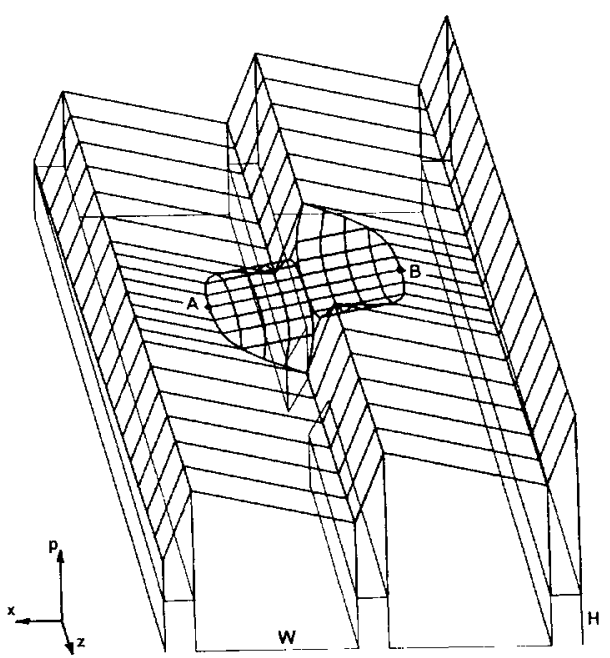

Fig. 5. Pressure generation in down-channel and in cross-channel direction.

Table 1. Expressions for Drag and Pressure Flow in Screw Elements, Based on the Total Metered Throughput, $Q$.

$$
\begin{aligned}
Q_{\text {channel }} & =(1-\alpha) Q_{d}+\varepsilon \cdot Q_{p i n}+Q_{p} \\
Q_{\text {channel }} & =Q+Q_{L}+Q_{L D} \\
-Q_{p} & =(1-\alpha) Q_{d}+\varepsilon \cdot Q_{p i n}-Q_{L}-Q_{L D}-Q \\
\alpha & =\left(d_{p i n}\right)^{2} /(L W / n) \quad \varepsilon=\text { efficiency parameter }
\end{aligned}
$$

pressure flow

$$
Q_{p}=-\frac{k_{t}}{\mu} \Delta p
$$

drag flow

$$
Q_{d}=f .1 / 2 \vee \cos \varphi H \pi D \sin \varphi F_{N} F_{D} F_{D C}
$$

leakage flow over flight

$$
Q_{L}=1 / 2 V \cos \varphi \delta r \pi D \sin \varphi F_{N} F_{D} F_{D C}
$$

leakage flow through flight

$$
Q_{L D}=1 / 2 \vee \cos \varphi H \pi D \sin \varphi(1-r) F_{N} F_{D} F_{D C}
$$

extra drag flow due to pins

$$
\begin{gathered}
Q_{\text {pin }}=n \vee H d_{p i n} \quad(\text { if } f=1) \\
V=\pi D N ; \quad r=\frac{L_{t}}{\pi D / \cos \varphi} ; \quad z=\frac{\ell}{\sin \varphi} ; \quad F_{N}=1-n e \\
k_{t}=\frac{1}{12 \ell} H^{3} \pi D F_{P C}\left(\sin ^{2} \varphi F_{N} F_{P}+(1-r) F_{P}^{\prime}\right) \quad F_{D}, F_{P}, F_{D C}, F_{P C} \text { (see Refs. 12, 13, and 14) }
\end{gathered}
$$




$$
\begin{gathered}
z=\ell / \sin \varphi \\
x=-l / \cos \varphi
\end{gathered}
$$

The total pressure flow equals

$$
\begin{aligned}
Q_{p}=-\frac{1}{12 \mu} H^{3} \pi D F_{P C} \\
\cdot\left[\sin \varphi F_{N} F_{P} \frac{d p}{d z}+\frac{(1-r)}{\cos \varphi} F_{P}^{\prime} \frac{d p}{d(-x)}\right]
\end{aligned}
$$

Combining Eq 6 with Eqs 4 and 5, the pressure flow is given by Eqs 5 and 11 of Table 1 . In Table $1, F_{D C}$ and $F_{P C}$ are correction factors that account for the influence of curvature on the flow in the kneaders' screw channels. The kneader has an $H / D$ of about 0.15 , which is rather large compared with most corotating twin-screw extruders where the $H / D<0.1$.

It is important to know what value of the geometrical constant $r$, expressing the relative remaining flight length, should be used in the calculations, since there are in principle two ways to determine $r$, as is demonstrated in Figs. $6 a$ and $6 b$. The results are shown in Table 2. The fact that two sets of $r$ values can be obtained will turn out to be important in the later evaluation of the experiments.

\section{MIXING}

The mixing qualities of the cokneader can be discussed as soon as the local conditions (expressed in the degree of fill $f$ ) are known from a more compre- hensive model. The number of reorientations can be calculated by starting with the analysis by Booy and Kafka (1), who consider the elementary passage of a single pin through the opening between two adjacent flights of a kneading element. Their assumptions are (i) the element is completely filled with melt, and (ii) after the passage of the pin, the material is - at least locally-reoriented, which can be expected from the simulations in Ref. 15.

The average residence time in a screw element with length $L$ is given by

$$
\bar{t}=\frac{\pi D L H(1-n e)}{Q}
$$

where $D=$ diameter, $H=$ channel depth, $n=$ the number of flights, $e=$ relative flight width, and $Q=$ throughput. The average residence time required for the passage of a pin between two flights (the length

Table 2. Geometrical Estimation of $r$, the Relative Remaining Flight Length, and Aspect Ratio $\alpha=\left(d_{\text {pin }}\right)^{2} /(L W / n)$ for Several Screw Elements.

\begin{tabular}{llll}
\hline & \multicolumn{3}{c}{$\begin{array}{c}r \\
\text { according to } \\
\text { Figure }\end{array}$} \\
\cline { 2 - 3 } & $\mathbf{6 a}$ & $\mathbf{6 b}$ & $\alpha$ \\
\hline conveying & 0.92 & 0.8 & 0.005 \\
c.c. kneading & 0.78 & 0.55 & 0.011 \\
kneading & 0.71 & 0.4 & 0.011 \\
\hline
\end{tabular}
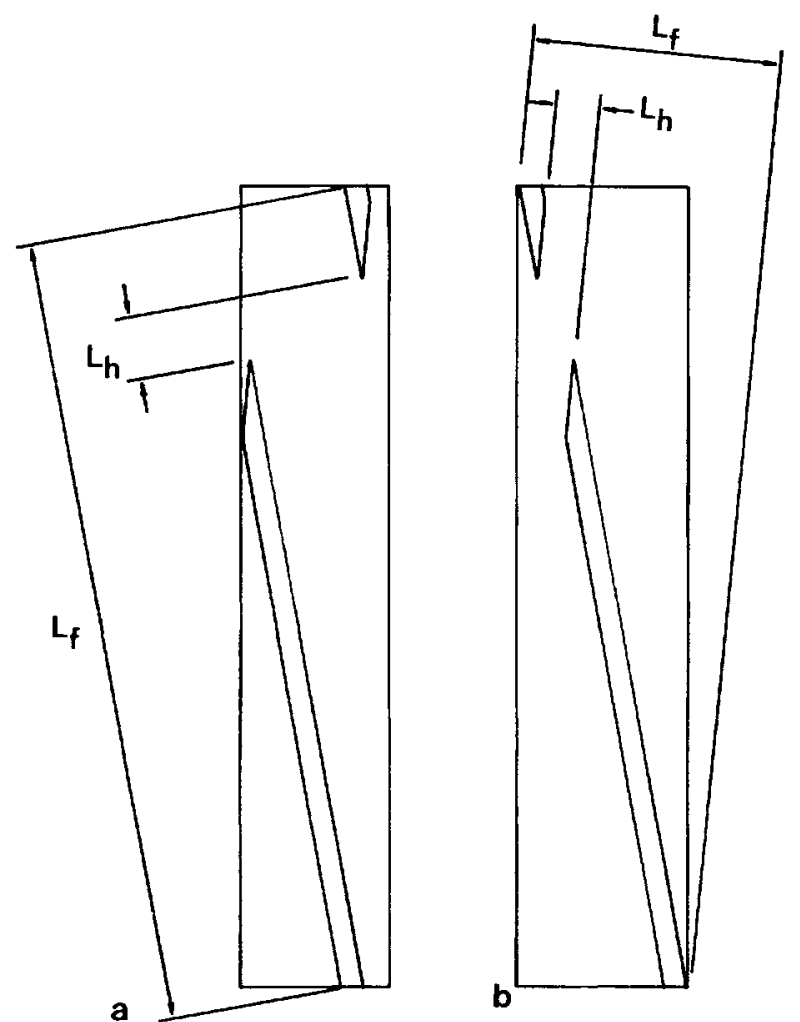
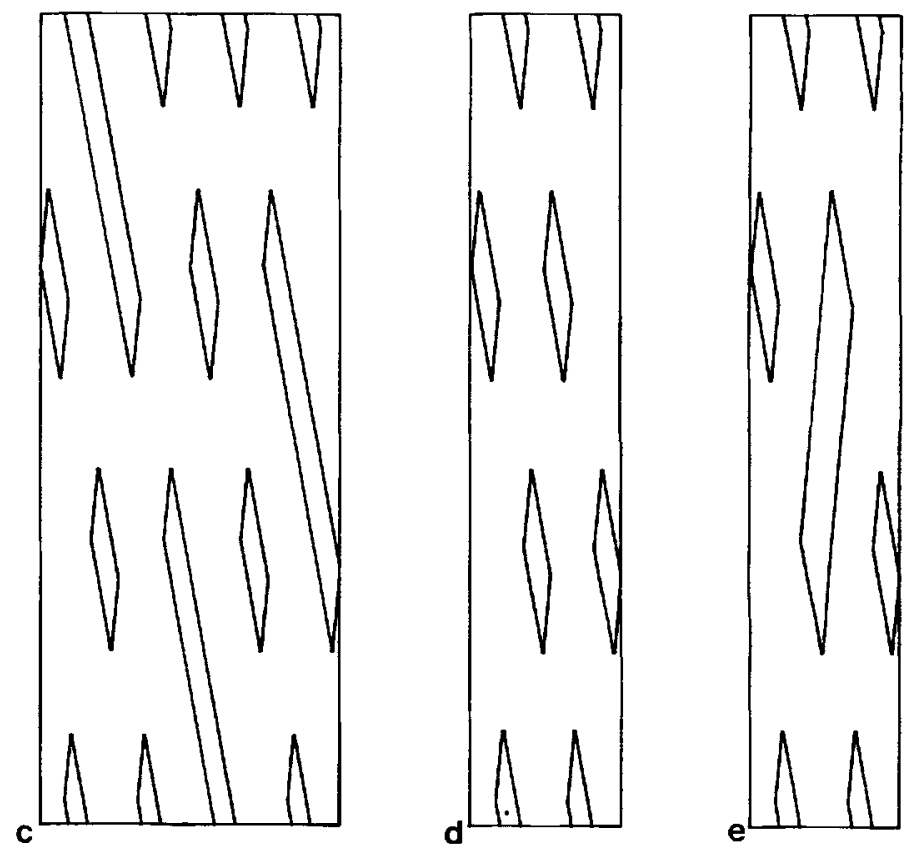

Fig. 6. Detail of unrolled screw channel: (a) conveying element, $L_{h} / L_{f}=(1-r) ;(b)$ conveying element, $L_{h} / L_{f}=(1-r) ;(c)$ closed channel kneading element; (d) kneading element; (e) as Fig. 6d, with locally negative pitch angle. 
of one flight is about $1 / 3$ the circumference) is given by

$$
\bar{t}_{p a s s}=\frac{1 / 3 \pi D}{1 / 2 \pi D N}=\frac{2}{3 N}
$$

where $N=$ screw speed $\left(\mathrm{s}^{-1}\right)$. The number of reorientations, $n r$, is given by

$$
n r=\frac{\bar{t}}{\bar{t}_{\text {pass }}}=3 / 2 \pi D L H(1-n e) \frac{N}{Q} .
$$

This analysis is valid if only one pin is present in the screw channel. However, in a real cokneader screw element, a total number of ' $p$ ' pins can be determined. For each element, $p$ can be obtained by multiplying the number of pins per lead of the screw by the number of pin rows on the barrel circumference (See Screw Geometry and Working Principle, above.) Thus, for closed channel kneading elements $p=3$, whereas for kneading elements $p=6$.

For the number of reorientations in a completely filled screw element, this yields the final expression (with $L=\pi D \tan \varphi$, the screw lead):

$$
n r=p .3 / 2 \pi^{2} D^{2} H \tan \varphi(1-n e) \frac{N}{Q} .
$$

In the case of partially filled screw elements, the number of reorientations is evaluated with respect to the filled length $L_{f}$ :

$$
n r=p .3 / 2 \pi D L_{f} H \tan \varphi(1-n e) \frac{N}{Q} .
$$

As an example, consider the completely filled kneading element ( $L=27 \mathrm{~mm}$ ) of a Buss PR46 laboratory cokneader, with typical data, as follows:

$$
\begin{aligned}
& \varphi=10.5 \text { degrees } \\
& H=7.10^{-3} \mathrm{~m} \\
& D=46.10^{-3} \mathrm{~m} \\
& n=2 \\
& e=0.133 \\
& N=240 \mathrm{rpm}=4 \mathrm{~s}^{-1} \\
& Q=20 \mathrm{~kg} \cdot \mathrm{h}^{-1} \approx 55.10^{-7} \mathrm{~m}^{3} \cdot \mathrm{s}^{-1} .
\end{aligned}
$$

With these data, the number of reorientations, calculated from $E q 11$, becomes $n r=128$. The amount of shear between two reorientations, $\gamma_{n}$, is estimated to be $\gamma=\dot{\gamma} \cdot t=2 / 3 \pi D / H \approx 14$.

\section{EXPERIMENTAL}

The goal of the experiments was threefold: (i) to provide a check for the geometrically estimated values of the relative remaining flight length; (ii) to determine the influence of the pins; (iii) to check the complete Newtonian, isothermal analysis of the kneader. To achieve this, extrusion experiments were performed using silicon oil $\left(\mu_{23^{\circ} \mathrm{C}}=1\right.$ Pa.s $)$ and paraffinic oil ( $\left.\mu_{23^{\circ} \mathrm{C}}=0.2 \mathrm{~Pa} . \mathrm{s}\right)$, under isothermal conditions. Throughput versus screw speed, throughput versus pressure generation as well as locally filled lengths were measured, using several screw types (conveying, closed channel kneading, and kneading), different number of pins mounted in the barrel wall (from 0 to max.), and varying processing conditions (screw speed, throughput). Finally, attempts were made to measure the pressure gradient directly; i.e., from the oil level in a series of open tubes along the cylinder. All experiments were performed on a PR 46-1 ID laboratory kneader, which could be fitted with a Plexiglas cylinder (see Fig. 7).

A problem arises when a constant kneader outflow is required, for instance for measuring the pumping characteristics $(Q-\Delta p)$ of the cokneader. The oscillatory motion of the kneader screw relative to the barrel causes severe pressure fluctuations. Usually a discharge extruder is needed to guarantee constant pressure at the die. This can be avoided by using a special die (11). The cylinder is fitted with a flange having the same boring as the kneader. A ring fitting closely inside this flange is mounted to the kneader shaft. The die opening now yields a constant pressure and consequently gives smooth filaments of constant diameter which can be cooled and cut. For measuring the pumping characteristic of the kneader, the resistance of the die is made adjustable and the pressure is measured using a manometer mounted at the end of the screw (see Fig. 8). The pumping characteristics of the screws as well as the filled lengths were measured using this special die.

\section{THROUGHPUT VERSUS PRESSURE CHARACTERISTIC}

Figures $9 a$ and $9 b$ show the throughput versus pressure characteristic for various screw elements. Note the large difference between conveying and kneading elements. The intersections with the vertical axis represent the net maximum outflow of the (completely filled) kneader. In this case, no die was present. This was done to prevent pressure generation due to the oscillation of the screw. Because relatively low viscous fluids were used, the experiments had to be corrected for gravity-induced flow.

The intersections with the horizontal axis yield the maximum pressure generating capacity of the screws. Here, the axial oscillatory motion was compensated for with the special die mentioned earlier. For conveying elements-single-flighted, i.e., having a much wider channel compared with the other double-flighted ones-no distinct influence of pins on either drag or pressure flow was observed.

With the equations of Table 1 and the data presented in Fig. 9, the two important parameters $r$ (relative remaining flight length) and $\varepsilon$ (efficiency parameter) can be evaluated.

Overall equation:

$$
\begin{gathered}
\begin{array}{c}
Q+Q_{L}+Q_{L D}=(1-\alpha) \cdot Q_{d}+\varepsilon \cdot Q_{p i n}+Q_{p} \\
\text { no pins: } \alpha=0, \varepsilon=0 \\
Q+Q_{L}+Q_{L D}=Q_{d}+Q_{p}
\end{array}
\end{gathered}
$$

The vertical intersection is calculated from the condition $Q_{p}=0$ : 


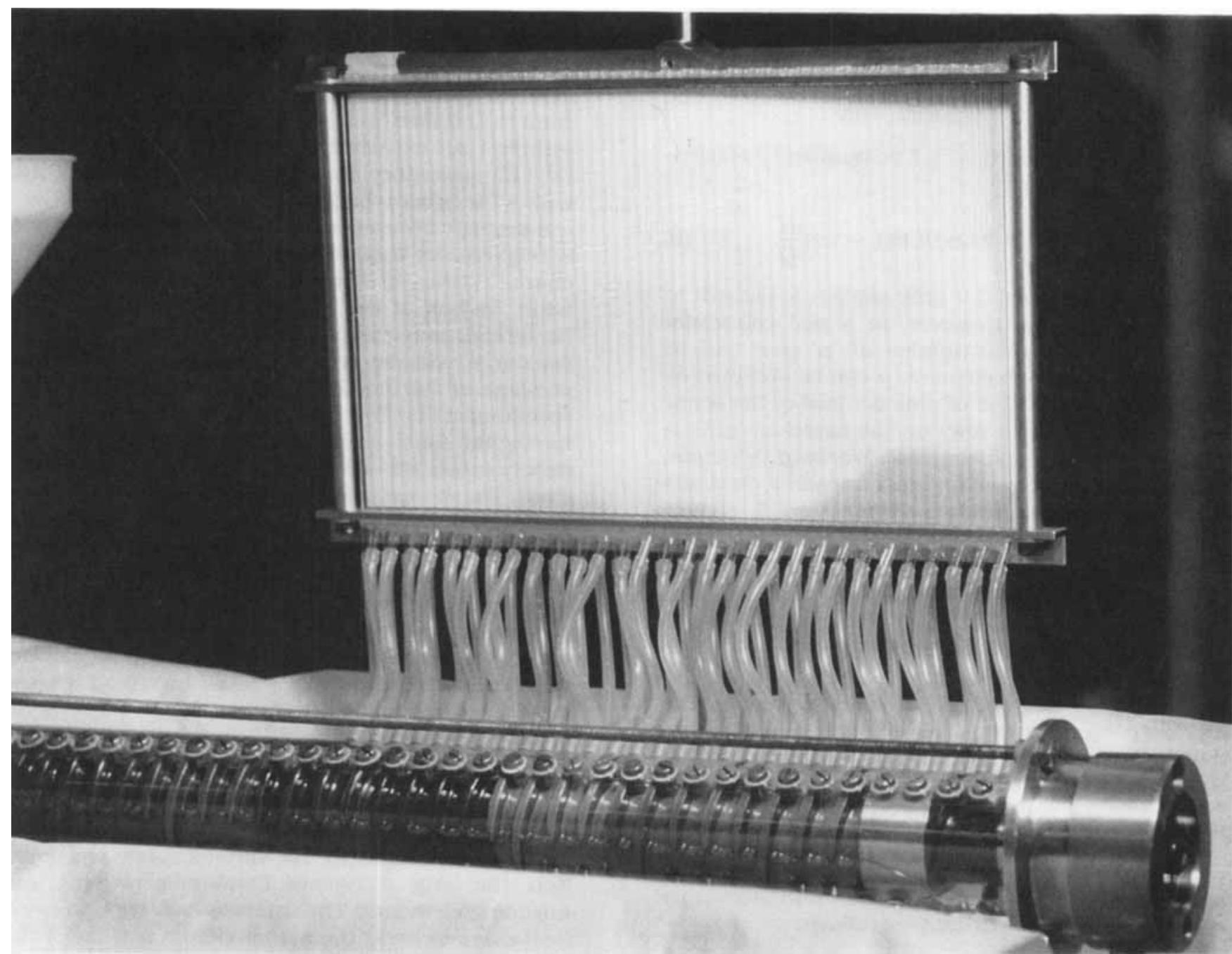

Fig. 7. The cokneader fitted with a Plexiglas cylinder. With a system of small glass tubes that act as open manometers. the pressure gradient along the cylinder can be visualized.

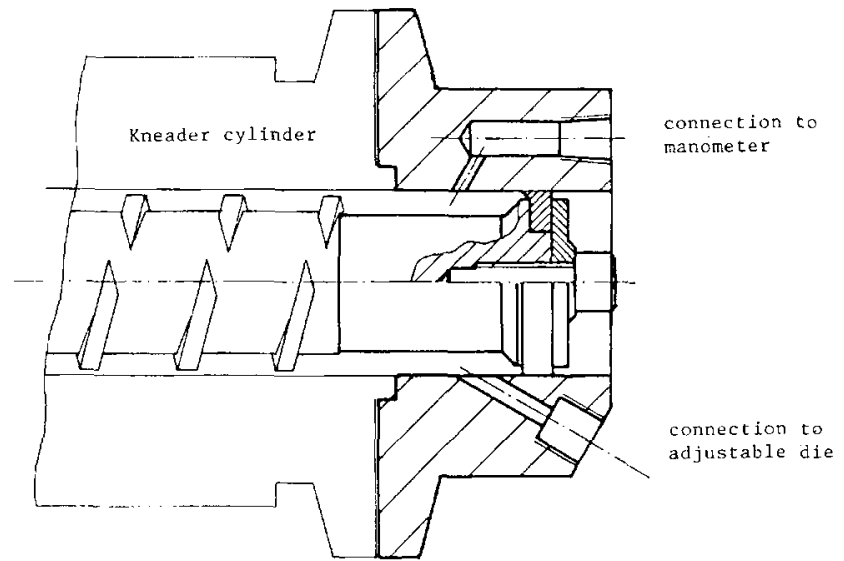

Fig. 8. Setup used to equalize pressure fluctuations due to the oscillatory motion of the screw.

$$
\begin{aligned}
Q & =Q_{d}-Q_{L}-\Theta_{L D} \\
& =Q_{d}(1-r \cdot \delta / H-(1-r)) \\
& =r \cdot Q_{d}(1-\delta / H)
\end{aligned}
$$

The horizontal intersection is calculated from the condition $Q=0$ :

$$
\begin{aligned}
-Q_{p} & =Q_{d} r \cdot(1-\delta / H) \\
\Delta p & =\frac{r \mu Q_{d}(1-\delta / H)}{k}
\end{aligned}
$$

with $k$ a function of $r: k=\left(\frac{C_{1} \cdot r}{C_{2}+C_{3} \cdot(1-r)}\right)^{-1}$ (see Eq 11 of Table 1).

$$
\begin{aligned}
& \text { with pins: } \alpha \neq 0, \varepsilon \neq 0 \\
& \qquad \begin{array}{l}
Q \\
+Q_{L}+Q_{L D}
\end{array}=(1-\alpha) Q_{d}+\varepsilon \cdot Q_{d}+Q_{p} .
\end{aligned}
$$

The vertical intersection $\left(Q_{p}=0\right)$ is given by

$$
Q=\frac{r \cdot Q_{a}(1-\delta / H)}{\left.Q\right|_{\alpha=0}}-\alpha \cdot Q_{a}+\varepsilon \cdot Q_{p i n} .
$$

The horizontal intersection $(Q=0)$ yields, analogous to $\mathrm{Eq} 17$, 

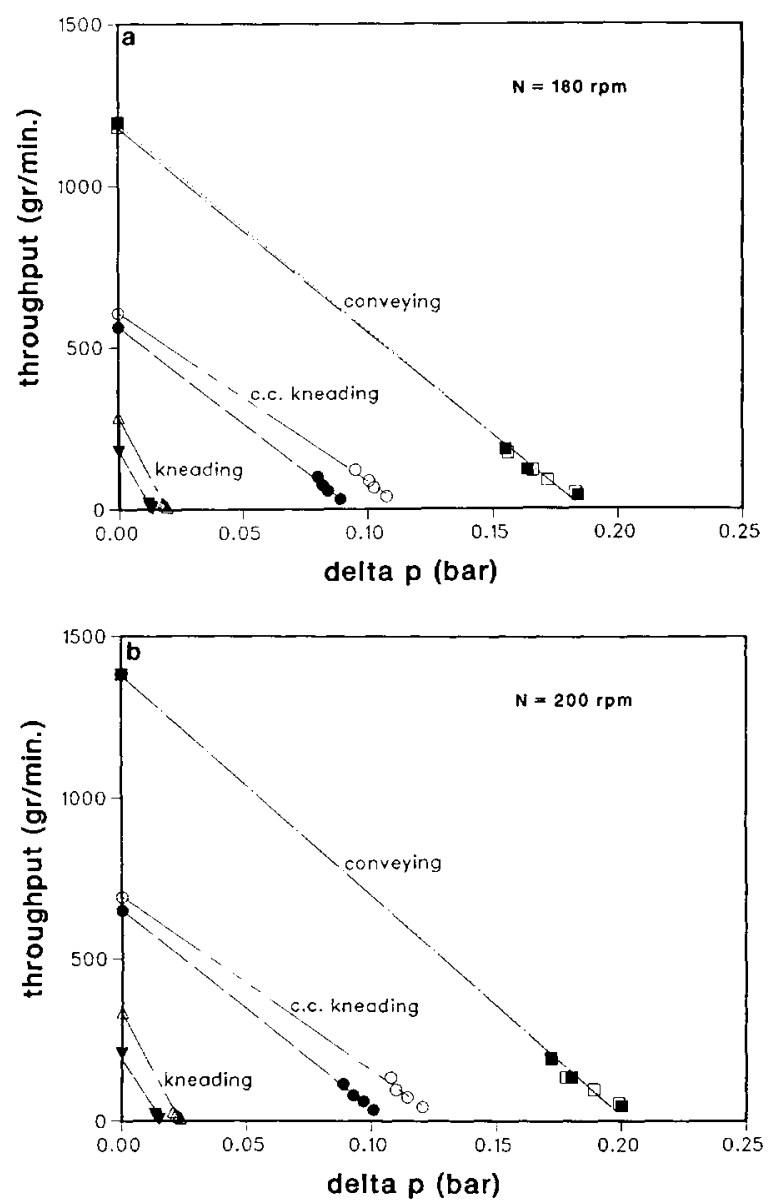

Fig. 9. Throughput versus pressure characteristics for conveying, closed channel kneading, and kneading screws in a 46-mm cokneader. Model liquids: silicon oil Rhodorsil V1OOO $\left(\mu_{23^{\circ} \mathrm{C}}=1\right.$ Pa.s) and paraffinic oil SUNPAR $2280\left(\mu_{23^{\circ} \mathrm{C}}=1\right.$ Pa.s). Parameters: Screw speed $N($ rpm $)$ and number of pin rows. (a) $N=180 \mathrm{rpm}$; (b) $N=200 \mathrm{rpm}$. Open resp. closed symbols: $\square$ conveying; $\bigcirc$ c.c. kneading: $\Delta \nabla$ kneading screw with resp. without pins.

$$
\Delta p=\frac{\frac{r \mu \cdot Q_{d}(1-\delta / H)}{k}}{\left.\Delta p\right|_{\alpha=0}}-\frac{\alpha \mu \cdot Q_{d}}{k}+\frac{\varepsilon \mu \cdot Q_{p i n}}{k} .
$$

Table 3 shows the values of $r$ and $\varepsilon$ that follow from the respective horizontal and vertical intersections.

In the case of conveying and closed channel kneading elements, the values of the experimentally determined relative remaining flight length (using Eqs 1220 ) as shown in Table 3 correspond reasonably well to those that can be determined from geometrical considerations. The results from the horizontal intersections correspond to the values in the first column of Table 2, whereas the results from the vertical intersections correspond well to the values in the second column of Table 2 . This can be explained by realizing that the pressure gradients in the cokneader are almost exclusively in the axial rather than the down-channel direction, because of the large number of holes. The values of the relative remaining flight length, calculated from the horizontal intersection
Table 3. Values for $r$ (Relative Remaining Flight Length) and $\varepsilon$ (Efficiency of Pins) as Determined from Horizontal and Vertical Intersections in Figure 9.

\begin{tabular}{lccccc}
\hline \multirow{2}{*}{ Intersection } & \multicolumn{2}{c}{$\boldsymbol{r}$} & \multicolumn{2}{c}{$\varepsilon$} \\
\cline { 2 - 3 } \cline { 5 - 6 } & (hor.) & (vert.) & (hor.) & (vert.) \\
\hline conveying & 0.93 & 0.75 & 0.01 & 0.01 \\
closed channel & & & & \\
$\quad$ kneading & 0.90 & 0.6 & 0.04 & 0.15 \\
kneading & 0.52 & 0.18 & 0.09 & 0.21 \\
\hline
\end{tabular}

will be close to the ones determined according to Fig. $6 a$. In the absence of pressure flow, the value of the relative remaining flight length is determined from drag flow, which is assumed to be present along the length of the flight in the down-channel direction. Consequently, the values of $r$ calculated from the vertical intersection correspond to the ones determined according to Fig. $6 \mathrm{~b}$. In the case of kneading elements, however, the length of the holes is so large in comparison with the remaining flight length that the model equations hardly apply.

With regard to the evaluation of the influence of pins as expressed in the efficiency parameter $\varepsilon$, we can conclude, as could be expected, that no improvement in transport properties in single-flighted elements is found. There is, however, an effect in the double-flighted elements (efficiency in the order of $10-20 \%)$. The experimental values of $\varepsilon$ also differ when determined from either vertical or horizontal intersection of the throughput-pressure characteristic. The naive statement of full effectivity of the transport capacity of pins expressed in the straightforward expression used $\left(Q_{p i n}=n V H d_{p i n}\right)$ is apparently an overestimation. This would be expected not only because of the bow-wave type of flow in front of a pin, but also because of the consideration that this flow is mainly in the tangential direction (straight through the holes in the flights), thus promoting leakage. The pins might seem less important; yet it must be kept in mind that pins are important for solids transport and that the presence of the pins is essential for mixing in the kneader.

\section{FILLED LENGTH}

The second way to evaluate the parameters $r$ and $\varepsilon$ can be realized with the setup shown in Fig. 7. By photographing the length of the channel that is completely filled, one can examine closely the combination of a basic screw element with a staggering element (Fig. 10).

Figures 11 a through $11 \mathrm{~d}$ show the comparison of experiments and calculations for the various processing conditions. In Fig. $11 \mathrm{a}$, the filled length is calculated for conveying screw elements without pins, using a value for the relative remaining flight length, $r=0.93$, obtained from the horizontal intersection (see Table 3 ). The calculated filled length is quite sensitive to the value of $r$. Figure $11 \mathrm{~b}$ shows calculated and measured filled lengths for conveying 


\section{P. H. M. Elemans and H. E. H. Meijer}

screw elements with pins. As could be expected from Fig. 9, no distinct influence of the pins on the filled length was observed.

For closed channel kneading elements without any pins, the value of $r=0.9$ (see the first column of Table 3 ) is correct to predict the filled length, as shown in Fig. 11c. If pins are mounted in closed channel kneading elements, a significant decrease in filled length is observed; see Fig. 11d. This effect is, however, not satisfactorily described by carrying out the calculations with an efficiency parameter $\varepsilon=$ 0.15 . Because the exact value of the filled length in closed channel kneading elements is difficult to dis-

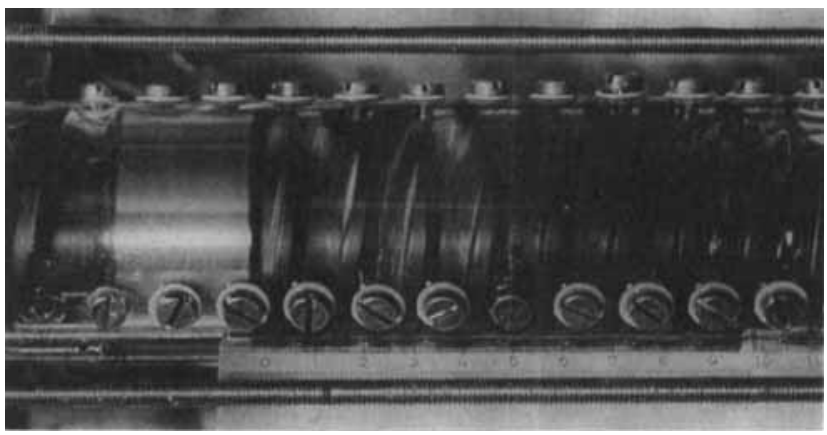

Fig. 10. Photograph showing the combination of a closed channel kneading screw element with 3 rows of pins and a Couette element (gap height $0.8 \mathrm{~mm}$ ).
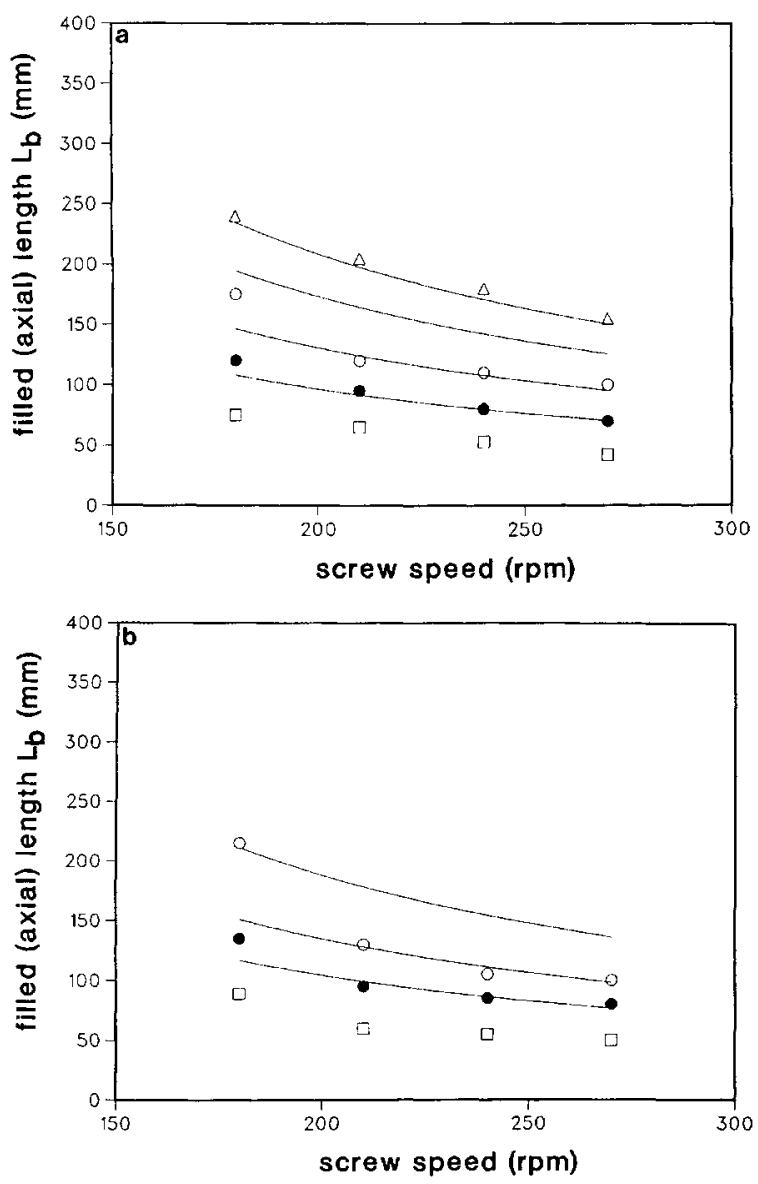
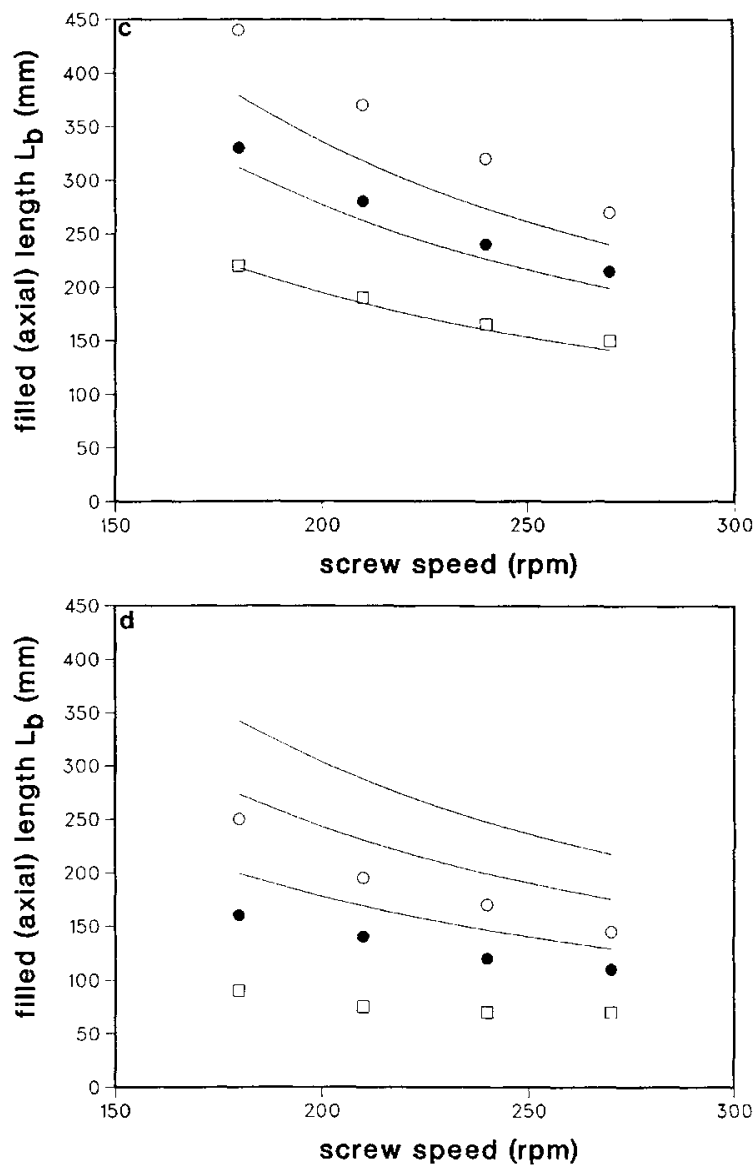

Fig. I1. (a) Comparison of calculated (drawn lines) and measured filled length $L_{b}$ for a combination of conveying screw elements (no pins) and a Couette element ( $r=0.93$; $\alpha, \varepsilon=O$ used in the calculations). Model fluid: paraffinic oil $\left(\mu_{25^{\circ} \mathrm{C}}=0.2\right.$ Pa.s). $Q$ (g/min): $\square 75.0 ; 0100: 0130 ; \triangle 150$. (b) as Fig. 11a. with pins ( $r=0.93 ; \alpha=0.005, \varepsilon=0.01) . Q$ (g/min): $\square$ 80; 100; O 140. (c) As Fig. 11a, for closed channel kneading elements (no pins, $r=0.9, \alpha, \varepsilon=0$ ). $Q$ (g/min): $\square$ 75: 100; O 120. (d) As Fig. 11a. for closed channel kneading elements (three rows of pins, $r=0.9 ; \alpha$ $=0.011, \varepsilon=0.15$ ).

cern from the photographs, the value of the parameter $\varepsilon$ will not be discussed further.

\section{PRESSURE GRADIENTS}

The third and most accurate way to evaluate $r$ is by visually investigating the axial pressure gradients with the setup shown in Figs. 7 and 12. From the data thus obtained, and with the equations of Table 1 , the relative remaining screw flight length $r$ can be calculated. The results are given in Table 4 for different screw geometries and processing conditions. (No pressure gradients were determined for kneading elements, because of the low pressure-generating capacity of these elements.)

To conclude the evaluation of $r$ and $\varepsilon$, Table 5 gives a listing of the values to be used in future calculations. With the model derived so far, it is now possible to calculate a sequence of screw elements with different combinations of screw speeds and throughputs. Figure 13 gives some examples of calculated 


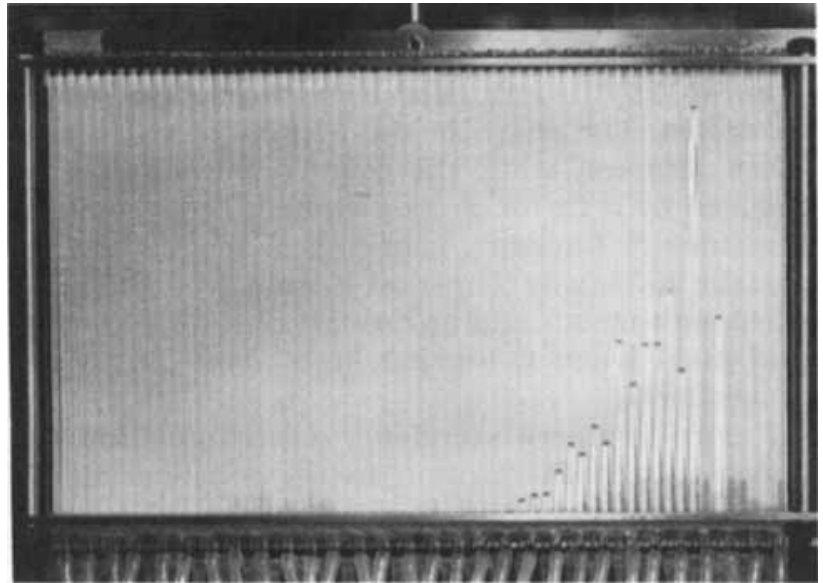

Fig. 12. Visualization of the pressure gradient in a closed channel kneading element, $N=250 \mathrm{rpm}, Q=270 \mathrm{~g} / \mathrm{min}$.

Table 4. Experimental Pressure Gradients and Relative Remaining Screw Flight Length $r$ in Conveying Elements (2 Rows of Pins) and Closed Channel Kneading Elements* (3 Rows of Pins).

\begin{tabular}{|c|c|c|c|c|}
\hline & $\begin{array}{l}Q(g / \\
\text { min) }\end{array}$ & $\underset{(\mathrm{rpm})}{N}$ & $\begin{array}{l}\frac{\Delta p}{L} \mid \exp . \\
(\mathrm{Pa} / \mathrm{m})\end{array}$ & $r$ \\
\hline \multirow[t]{3}{*}{ conveying } & 170 & 150 & 5390 & 0.88 \\
\hline & 170 & 200 & 11590 & 0.92 \\
\hline & 200 & 150 & 5120 & 0.88 \\
\hline \multirow{6}{*}{ c.c. kneading } & 170 & 150 & 2680 & 0.82 \\
\hline & 170 & 200 & 4200 & 0.83 \\
\hline & 170 & 250 & 5340 & 0.83 \\
\hline & 270 & 150 & 1700 & 0.77 \\
\hline & 270 & 200 & 3020 & 0.80 \\
\hline & 270 & 250 & 4390 & 0.81 \\
\hline
\end{tabular}

* Efficiency parameter $\varepsilon=0.15$ used in the calculations.

Table 5. Concluding Values for $r$ (Relative Remaining Flight Length) and $\varepsilon$ (Efficiency of Pins) for Several Screw Elements.

\begin{tabular}{lcc}
\hline & $r$ & $\varepsilon$ \\
\hline conveying & 0.9 & 0.01 \\
c.c. kneading & 0.8 & 0.15 \\
kneading & 0.2 & 0.21 \\
\hline
\end{tabular}

pressure profiles in common screw configurations for various processing conditions.

\section{NONISOTHERMAL, NON-NEWTONIAN ANALYSIS}

Analogous to the analysis in Ref. 3, the Newtonian isothermal analysis of the cokneader can be extended to the nonisothermal, non-Newtonian case. By taking incremental steps over the length of the kneader, more quantitative answers concerning specific energy and temperature rise can be given. Over each incremental step, a heat balance is solved: the heat stored in the local volume (resulting in a temperature rise) equals the dissipative heat generated by the velocity gradients plus the heat exchanged with the walls (positive or negative). Figure 14a shows the pressure profiles and filled lengths for constant
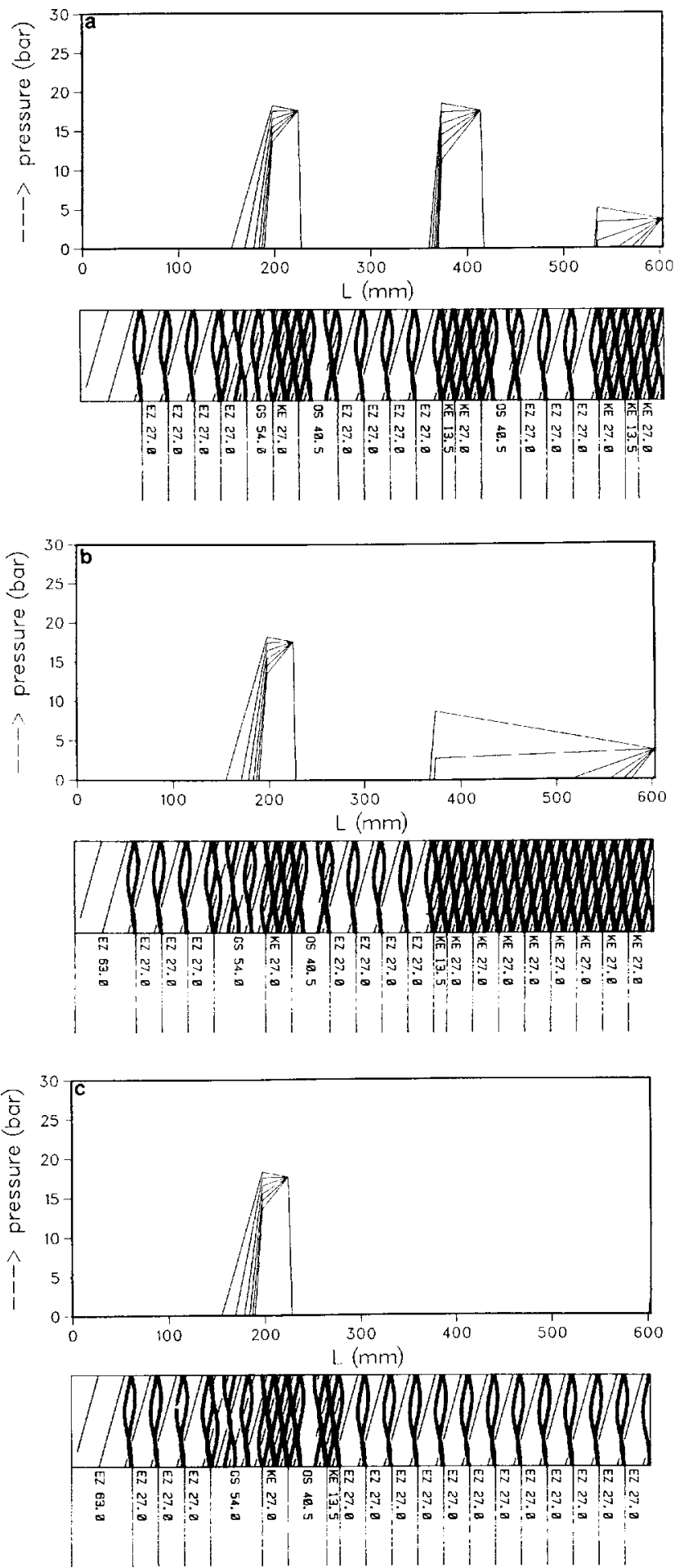

Fig. 13. (a) Calculated pressure profile and filled lengths in a cokneader $(D=46 \mathrm{~mm})$ with standard screw geometry. Modelfluid: linear low-density polyethylene. Newtonian, isothermal model. Parameter: Screw speed. Throughput $Q=25 \mathrm{~kg} / \mathrm{h}$. (b) As Fig. 13a, with kneading screw. (c) As Fig. 13a, with conveying screw.

throughput with varying screw speed. Figure $14 b$ shows the temperature profile for the same throughput, with variation of initial melt temperature. No experiments with polymer melts were performed. 

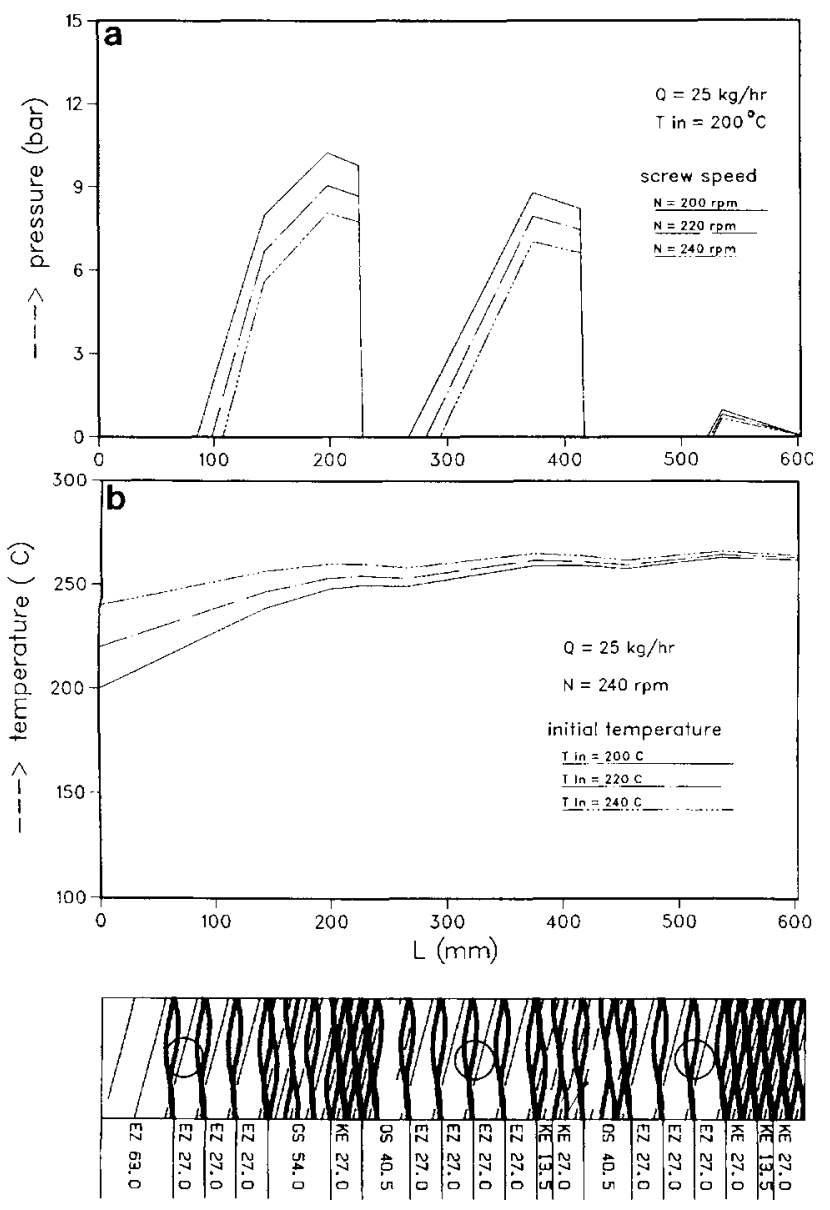

Fig. 14. (a, top) Calculated pressure profile and filled lengths in a cokneader $(D=46 \mathrm{~mm})$. Model fluid: linear low-density polyethylene, $\left.\mu_{0}\right|_{200^{\circ} \mathrm{C}}=5000 \mathrm{~Pa} . \mathrm{s} ; b=0.016$ : $n=0.43$. $T_{\text {wall }}=200^{\circ} \mathrm{C}$. Parameter: screw speed. $(b$, bottom) Calculated end temperatures in a cokneader $(D=46$ $\mathrm{mm}$ ). Modelfluid is as in Fig. 14a, parameter: initial melt temperature.

\section{RESIDENCE TIME DISTRIBUTION}

Apart from their local pressure-generating or pressure-consuming capacity, the different screw geometries of the cokneader can be characterized by their residence time distribution $R T D(16,17)$, provided the completely filled lengths are known. Some representative results from Ref. 18 will be discussed.

At a given moment during the compounding process-in the experiments, poly(vinyl chloride) (PVC) VARLAN (DSM) is used-titanium dioxide $\left(\mathrm{TiO}_{2}\right)$ tracer particles are added as a pulse at the entrance of the extruder. At the exit, samples are taken from the strand at regularly spaced intervals in time $(\Delta t=$ 7.5 s). From the amount of tracer material that can be detected in the sample via $X$-ray fluorescence (with an accuracy of $1 \mathrm{ppm}$ ), the response is determined. The results are presented in dimensionless form. The value of the cumulative response $F$ at a time $t$ represents the fraction of the material with a residence time less than $t$. It is clear that $F \rightarrow 1$ as $t$ approaches infinity. It is common to plot $F(t)$ versus the dimensionless time $t / \bar{t}$, where $\bar{t}$ is the average residence time.

In Fig. 15, the influence of the throughput is demonstrated. The shape of the $F(t)$ curve remains almost constant, while the mean residence time $\bar{t}$ is reduced by a factor 2 , as expected: By assuming a sequence of kneading elements of length $260 \mathrm{~mm}$ and the buffle ring elements $(40 \mathrm{~mm}$ ) to be completely filled with melt, $t$ can be estimated $(E q 7)$ to be $80 \mathrm{~s}$ and $40 \mathrm{~s}$ when $Q=12.5 \mathrm{~kg} \cdot \mathrm{h}^{-1}$ and $25 \mathrm{~kg} \cdot \mathrm{h}^{-1}$. respectively.

Figure 16 shows a tendency toward plug flow (i.e., a more narrow distribution) for the nonadhering PVC grade. Figures 17 and 18 show an overall comparison between the most common screw geometries.

\section{DISCUSSION}

It is shown that an analysis similar to that for the corotating twin-screw extruder can be used to model the flow in a Buss cokneader. Measurements of the throughput versus pressure characteristics, the filled lengths and, most accurately, the pressure gradients are effective ways to check and evaluate important geometrical parameters such as the effective relative

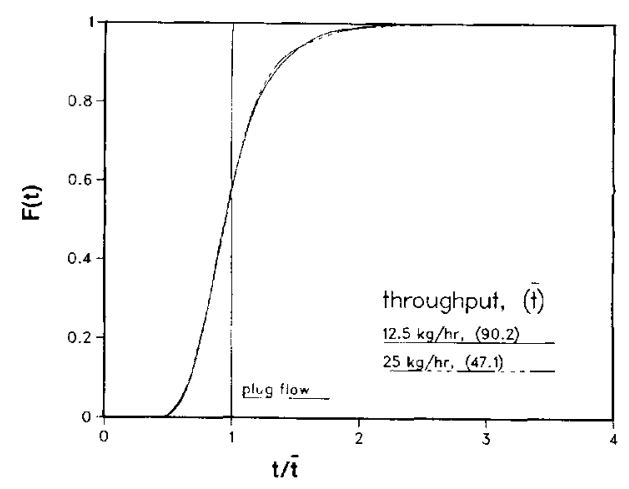

Fig. 15. Residence time distribution in a PR-46 Buss cokneader. Screw speed, $N=200 \mathrm{rpm}$; barrel temperature $T_{w}=150^{\circ} \mathrm{C}$; kneading screw geometry (see also Fig. 13). Parameter: metered throughput $Q$.

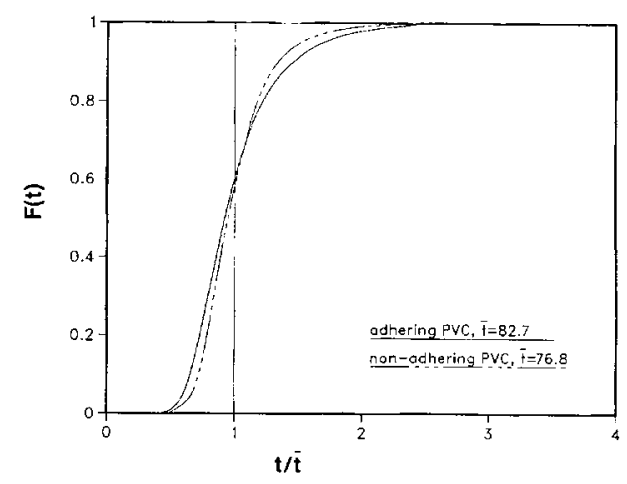

Fig. 16. As Fig. 15. Processing conditions: $Q=12.5 \mathrm{~kg} /$ $h, N=200 \mathrm{rpm}, T_{w}=150^{\circ} \mathrm{C}$; standard screw geometry. Material: PVC with internal and external lubricants, referred to as "adhering" and "nonadhering" (DSM VARLAN S 5020 and S 7120, respectively). 


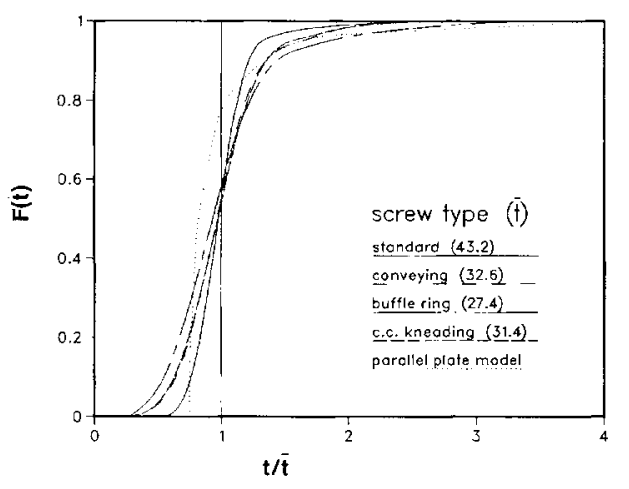

Fig. 17. As Fig. 15. Processing conditions: $Q=37.5 \mathrm{~kg} /$ $h, N=200 \mathrm{rpm}, T_{w}=150^{\circ} \mathrm{C}$. Parameter: screw geometry. The dotted line represents $F(t)$ for a single-screw extruder, as predicted by Pinto and Tadmor (17).

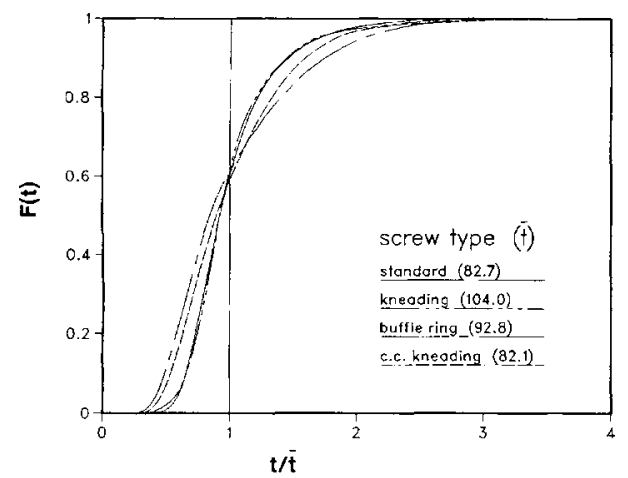

Fig. 18. As Fig. 17. Processing conditions: $Q=12.5 \mathrm{~kg} /$ h. $N=100 \mathrm{rpm} . T_{w}=150^{\circ} \mathrm{C}$.

remaining flight length and the influence of the pins on drag and pressure flow. Extension of the model to nonisothermal, power-law calculations is possible. It will be important to model in yet more detail the dissipation of heat in the narrow gaps between pins and screw flights as well as the increased heat exchange between the polymer and the kneader wall. On a local scale, a finite-element-method calculation might be a helpful tool in understanding these phenomena. Further experiments, such as determination of critical screw speed and temperature profile in the kneader, are needed to evaluate the extended model.

\section{APPENDIX}

Also in the case of corotating twin-screw extruders, especially for non-neutral kneading elements, the axial pressure flow through the holes must be incorporated in the general expression for the pressure flow. Therefore, the Tables $4 a$ and $4 b$ of Ref. 3 are to be replaced by:

Definition:

$$
\begin{aligned}
Q_{\text {channel }} & =Q_{d}+Q_{p} \\
Q_{\text {channel }} & =Q+Q_{L}+Q_{L D} \\
-Q_{p} & =\left(Q_{d}-Q_{L}-Q_{L D}\right)-Q
\end{aligned}
$$

with pressure flow

$$
Q_{p}=\frac{k_{t}}{\mu} \Delta p
$$

drag flow

$$
B_{d}=1 / 2 V \cos \varphi H \pi D \sin \varphi F_{N} F_{D} F_{D C}
$$

leakage flow (over flights)

$$
Q_{L}=1 / 2 V \cos \varphi \delta \mathrm{r} \pi D \sin \varphi F_{N} F_{D} F_{D C}
$$

leakage flow (through flights)

$$
\Theta_{L D}=1 / 2 V \cos \varphi H(1-r) \pi D \sin \varphi F_{N} F_{D} F_{D C}
$$

$V=\pi D N ; \quad r=\frac{L_{f}}{\pi D / \cos \varphi}$

$F_{N}=\frac{2 n-1}{n}(1-n e) ; \quad z=\frac{\ell}{\sin \varphi}$

$k_{t}=\frac{1}{12 \ell} H^{3} \pi D F_{P C}\left[\sin ^{2} \varphi F_{N} F_{P}+(1-r) F_{P}{ }^{\prime}\right]$

$F_{D}, F_{P}, F_{D C}, F_{P C}$ correction factors (see Ref. 14)

transport element: $r=1 ; 0<\varphi<180^{\circ}$

kneading element: $0<r<1 ; 0<\varphi<180^{\circ}$

\section{ACKNOWLEDGMENT}

The authors want to thank $H$. Truijen and L. Krijger for their support in the modeling experiments, and M. Sih for the computer modeling.

\section{NOMENCLATURE}

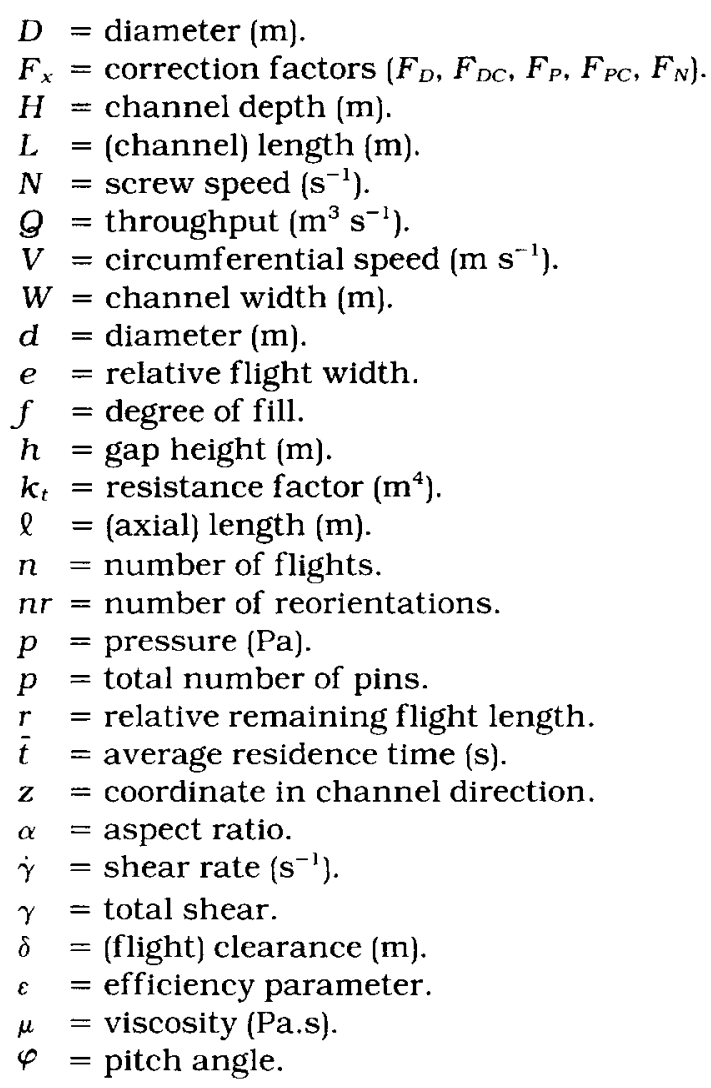




\section{P. H. M. Elemans and H. E. H. Meijer}

\section{Subscripts}

$D=\operatorname{drag}\left(Q_{D}, F_{D}\right)$.

$D C=$ drag, (due to) curvatuve $\left(F_{D C}\right)$.

$f=$ flight $\left(L_{f}\right)$.

$h=$ hole $\left(L_{h}\right)$.

$o=$ reference $\left(\mu_{o}\right)$.

$L=$ leakage (overflights) $\left(Q_{L}\right)$.

$L D=$ leakage (throughflights) $\left(Q_{L D}\right)$.

$N=$ number of flights $\left(F_{\mathrm{N}}\right)$.

$P=$ pressure $\left(Q_{p}, F_{\mathrm{p}}\right)$.

$P C=$ pressure, (due to) curvature $\left(F_{P C}\right)$.

\section{REFERENCES}

1. M. L. Booy and F. Y. Kafka, SPE ANTEC Tech. Papers, 33, 87 (1987).

2. J. Jeisy. Y. Trouilhet, and P. Grassman, Verfahrenstechnik, 10/2, 79 (1976).

3. H. E. H. Meijer and P. H. M. Elemans, Polym. Eng. Sci., 28,275 (1988)

4. P. Schnottale, Kautschuk Gummi Kunststoffe, 38, 2/85. 116 (1985).
5. S. Jakopin, Adv. Polym. Technol. 3 (4), 365-381.

6. S. Jakopin and P. Franz, presented at the AIChE Diamond Jubilee. Washington, D.C. (November 3, 1983).

7. D. B. Todd and J. W. Hunt, SPE ANTEC Tech. Papers, 19, 577 (1973).

8. German Patent 944727 (H. List, 1945).

9. R. Brzoskowski, J. L. White, W. Szydlowski, N. Nakajima, and K. Min, Int. Polym. Proc. III, 3, 134 (1988).

10. E. G. Harms, dissertation RWTH Aachen, West Germany (1981).

11. U.S. Patent 3642406 (H. F. Irving, 1971).

12. C. Rauwendaal, Polymer Extrusion, Hanser Publishers, Munich (1986).

13. J. M. McKelvey, Polymer Processing, John Wiley \& Sons, New York (1962).

14. Z. Tadmor and 1. Klein, Engineering Principles of Plas ticating Extrusion, Van Nostrand Reinhold, New York City (1971).

15. L. Erwin and F. Mokhtarian, Polym. Eng. Sci., 23, 49 (1983).

16. P. V. Danckwerts, Chem. Eng. Sci., 2, 1 (1953); Ibid., 8, 93 (1958).

17. G. Pinto and Z. Tadmor, Polym. Eng. Sci., 10, 279 (1970).

18. A. Engbersen (DSM), private communications (1986). 